\title{
Metabolic Acidosis in Critically IIl Cirrhotic Patients with Acute Kidney Injury
}

\author{
Dan-Qin Sun\#1,2, Lai Zhang ${ }^{\# 1}$, Chen-Fei Zheng ${ }^{3}$, Wen-Yue Liu ${ }^{4}$, Kenneth I. Zheng ${ }^{5}$, Xiao- \\ Ming Chen ${ }^{6}$, Ming-Hua Zheng* ${ }^{5,7,8}$ and Wei-Jie Yuan*2
}

${ }^{1}$ Department of Nephrology, The Affiliated Wuxi No. 2 People's Hospital of Nanjing Medical University, Wuxi, China; ${ }^{2}$ Department
of Nephrology, Shanghai General Hospital of Nanjing Medical University, Shanghai, China; ${ }^{3}$ Department of Nephrology, The First
Affiliated Hospital of Wenzhou Medical University, Wenzhou, China; ${ }^{4}$ Department of Endocrinology, The First Affiliated Hospital of
Wenzhou Medical University, Wenzhou, China; ${ }^{5}$ NAFLD Research Center, Department of Hepatology, the First Affiliated Hospital of
Wenzhou Medical University, Wenzhou, China; ${ }^{6}$ Zhejiang Engineering Research Center of Intelligent Medicine, The First Affiliated
Hospital of Wenzhou Medical University, Wenzhou, China; ${ }^{7}$ Institute of Hepatology, Wenzhou Medical University, Wenzhou,
China; ${ }^{8}$ Key Laboratory of Diagnosis and Treatment of Severe Hepato-Pancreatic Diseases of Zhejiang Province, Wenzhou, China

\section{Abstract}

Background and Aims: The metabolic acid-base disorders have a high incidence of acute kidney injury (AKI) in critically ill cirrhotic patients (CICPs). The aims of our study were to ascertain the composition of metabolic acidosis of CICPs with AKI and explore its relationship with hospital mortality. Methods: Three-hundred and eighty consecutive CICPs with AKI were eligible for the cohort study. Demographic, clinical and laboratory parameters were recorded and arterial acid-base state was analyzed by the Stewart and Gilfix methodology. Results: Net metabolic acidosis, lactic acidosis, acidosis owing to unmeasured anions, acidemia, and dilutional acidosis were less frequent in the non-survival group compared to the survival group of CICPs. The presence of acidemia, acidosis owing to unmeasured anions, and lactic acidosis were independently associated with increased risk of intensive care unit 30-day mortality, with hazard ratios of 2.11 (95\% confidence interval (CI): 1.43-3.12), 3.38 (95\% CI: $2.36-4.84$ ), and 2.16 (95\% CI: $1.47-3.35$ ), respectively. After full adjustment for confounders, the relationship between acidosis owing to unmeasured anions with hospital mortality was still significant, with hazard ratio of 2.29 (95\% CI: 1.22-4.30). Furthermore, arterial lactate concentration in combination with chronic liver failure-sequential organ failure assessment and $\mathrm{BE}_{\mathrm{UMA}}$ had the strongest ability to differentiate 30-day mortality (area under the receiver operating characteristic curve: $0.79,95 \% \mathrm{CI}: 0.74-0.83$ ).

Keywords: Metabolic acidosis; Critically ill cirrhotic patients; Acute kidney injury Hospital morality.

Abbreviations: AKI, acute kidney injury; AG, anion gap; AUROC, area under the receiver operating characteristic curve; $\mathrm{BE}$, base excess; $\mathrm{CI}$, confidence interval; CICPs, critically ill cirrhotic patients; CLIF-SOFA, chronic liver failure-sequentia organ failure assessment; $\mathrm{HCO}^{3-}$, bicarbonate; ICU, intensive care unit; KDIGO kidney disease improving global outcomes; MIMIC-III v3.0, Multiparameter Intelligent Monitoring in Intensive Care Database III version 3.0; SAPS, simplified acute physiology score; $\mathrm{SCr}$, serum creatinine; SIDa, strong ion differenceapparent; SIDe, strong ion difference-effective; SIG, strong ion gap.

Received: 22 March 2019; Revised: 20 April 2019; Accepted: 22 April 2019 \#These authors contributed equally to this work.

*Correspondence to: Wei-Jie Yuan, Department of Nephrology, Shanghai General Hospital, Nanjing Medical University, Shanghai 200080, China. E-mail: ywj4196@163.com; Ming-Hua Zheng, Department of Hepatology, NAFLD Research Center, The First Affiliated Hospital of Wenzhou Medical University; No. 2 Fuxue Lane, Wenzhou 325000, China. E-mail: zhengmh@wmu.edu.cn
Conclusions: CICPs with AKI exhibit a complex metabolic acidosis during intensive care unit admission. Lactic acidosis and $\mathrm{BE}_{\mathrm{UMA}}$, novel markers of acid-base disorders, show promise in predicting mortality rate of CICPs with AKI.

Citation of this article: Sun DQ, Zhang L, Zheng CF, Liu WY, Zheng KI, Chen XM, et al. Metabolic acidosis in critically ill cirrhotic patients with acute kidney injury. J Clin Transl Hepatol 2019;7(2):112-121. doi: 10.14218/JCTH.2019.00013.

\section{Introduction}

Acute kidney injury (AKI) is defined by rapid kidney function decline, over several hours to days, with contradistinction to chronic kidney disease. ${ }^{1}$ It is a common complication of critically ill cirrhotic patients (CICPs) and is a common reason for which CICPs are admitted to the intensive care unit (ICU). ${ }^{2,3}$ In patients with stable cirrhosis, studies have found that hypoalbuminemic alkalosis, dilutional acidosis and hyperchloremic acidosis work together to achieve a compensatory effect, in which alkalizing and acidifying acid-base disturbances can achieve an equilibrium that eventually results in a stable metabolic acid-base state. ${ }^{4,5}$

No data to date is available for disorders of acid-base homeostasis in CICPs with AKI. Acid-base data have been interpreted by traditional methods that contain the parameters of standard base excess, bicarbonate $\left(\mathrm{HCO}^{3-}\right)$, anion gap (AG), and $\mathrm{pH}^{6}$ The standard base excess, a calculated data value, assumes normal plasma protein and electrolyte content. $^{7}$ The observed $A G$ also ignores the role of major non-bicarbonate buffers in blood plasma, such as plasma proteins and inorganic phosphate. ${ }^{8}$ However, CICPs with AKI always present with electrolyte and protein abnormalities. Thus, the physicochemical approach performed by Stewart for acid-base disturbances has been applied in clinical practice, particularly for critically ill patients. ${ }^{9}$

In addition, the Gilfix methodology, a simple bedside approach based on the fundamental principles of the Stewart method, can be used to analyze base excess compounds. ${ }^{10}$ The Gilfix method proposed that non-respiratory acid-base disturbance may be attributed to the following: changes in strong ions due to free water deficit or excess, determined by changes in sodium concentration, and changes in chloride 
concentration; changes in protein charges (mainly albumin); and presence of unmeasured organic anions. ${ }^{11,12}$ Although the Stewart model theory and the Gilfix method have been used previously to better understand acid-base homeostasis in critically ill patients, ${ }^{13,14}$ there has been no report to evaluate their ability to predict mortality in CICPs with AKI.

It is generally understood that one cannot separate acidbase effects of CICPs from AKI; therefore, comprehending the contribution of AKI to acid-base disorders becomes essential to opening avenues for novel screening methods that may provide better physiological diagnosis and prognosis. This study aims to identify and describe the composition of metabolic acidosis in CICPs with AKI and their relationship with hospital mortality.

\section{Methods}

\section{The database and patients}

The data for this study was extracted from the Medical Information Mart for Intensive Care version 3.0 (MIMIC-III v3.0), a comprehensive and free database. With permission, we were allowed access to medical records of patients treated in the ICU from 2001 to 2012 at Beth Israel Deaconess Medical Center (our certification number: 1605699). The data used were non-patient identifiable and anonymous; detailed descriptions have been reported in our previous studies. ${ }^{15,16}$

In this study, we extracted a total of 1460 consecutive CICPs from the MIMIC-III v3.0 database. Ultimately, 380 in-hospital patients in the ICU were deemed eligible for study inclusion. Criteria for inclusion were as follows: diagnosis of liver cirrhosis and older than 18 years; diagnosis of AKI followed-up for at least 30 days; no history of liver transplantation; no history of end-stage renal disease; no regular renal replacement therapy; and admitted to the hospital for more than $24 \mathrm{~h}$.

CICPs, defined as patients with critically ill cirrhosis, were enrolled in our study when admitted to the ICU. The criteria of liver cirrhosis and AKI in the present study were described in our previous studies. ${ }^{15-17}$ For patients without a serum creatinine ( $\mathrm{SCr}$ ) value prior to hospitalization, we used the first $\mathrm{SCr}$ value measured during hospitalization as the baseline $\mathrm{SCr}$, in compliance with recommendations of the International Club of Ascites. ${ }^{18}$ In addition, the models for end-stage liver disease (commonly known as MELD), chronic liver failuresequential organ failure assessment (CLIF-SOFA), simplified acute physiology score (commonly known as SAPS II), SOFA score, and kidney disease improving global outcomes (commonly known as KDIGO) criteria were calculated to evaluate the severity of CICPs with AKI.

\section{Sampling and blood analysis}

Our investigators extracted detailed patient records, typically containing demographic and laboratory parameters as well as survival time. The clinical parameters were derived from the hospital's online information systems. The laboratory parameters from routine tests on admission were extracted into a relational database. Patient arterial blood was collected on admission. SCr was evaluated upon admission and at least once every $24-\mathrm{h}$ interval. The urine output was calculated for the first $24 \mathrm{~h}$ after ICU admission, recorded at least $6 \mathrm{~h}$ intervals. Social Security Death Records from the USA government provided the time of death. Patient data was obtained using Oracle Structured Query Language Developer version 3.0 (Oracle Corporation, Redwood Shores, CA, USA).

\section{Acid-base analysis}

Arterial $\mathrm{HCO}^{3-}$, standard bicarbonate $\left(\mathrm{HCO}^{3-}{ }_{\text {st }}\right)$, base excess $(\mathrm{BE})$ and standard base excess measurements were carried out according to Henderson-Hasselbach and Siggaard-Andersen equations respectively. ${ }^{19}$ In the present study, $\mathrm{pH}<7.35$ was defined as acidemia, $\mathrm{pH}>7.45$ as alkalemia, $\mathrm{HCO}^{3-}<22$ $\mathrm{mmol} / \mathrm{L}$ as net metabolic acidosis, $\mathrm{HCO}^{3-}>26 \mathrm{mmol} / \mathrm{L}$ as alkalosis, and lactate $>2.2 \mathrm{mmol} / \mathrm{L}$ as lactic acidosis.

Acid-base analysis was performed using Stewart equations and the Gilfix methodology. In the Gilfix methodology, lactate levels, unmeasured anions, hypoalbuminemia, chloride levels, and changes of plasma can influence BE. Based on this concept, we calculated the BE compounds in comparison with the effects of electrolytes, albumin, lactate and unmeasured anions. ${ }^{10,14}$ The means of reference values were used as normal values. The effective strong ion difference was necessary for the role of weak acids $\left(\mathrm{CO}_{2}\right.$, albumin, and phosphate) in the balance of electrical charges in plasma.

\section{Calculated acid-base variables}

1) $\mathrm{BE}$ caused by free water effect $\left(\mathrm{BE}_{\mathrm{Na}}\right)=0.3 \times$ $\left(\mathrm{Na}-\mathrm{Na}_{\text {normal }}\right) ; \mathrm{Na}_{\text {normal }}=140 \mathrm{mmol} / \mathrm{L}, \mathrm{BE}_{\mathrm{Na}}<-5$ $\mathrm{mmol} / \mathrm{L}$ was defined as dilutional acidosis, and $\mathrm{BE}_{\mathrm{Na}}$ $>+5 \mathrm{mmol} / \mathrm{L}$ as concentrational alkalosis, respectively.

2) $\mathrm{Cl}_{\text {Na-corrected }}=\mathrm{Cl} \times \mathrm{Na}_{\text {normal }} / \mathrm{Na} ; \mathrm{BE}_{\mathrm{Cl}}=\mathrm{Cl}_{\text {normal- }}$ $\mathrm{Cl}_{\text {Na-corrected }} \mathrm{BE}_{\mathrm{Cl}}<-5 \mathrm{mmol} / \mathrm{L}$ was defined as hyperchloremic acidosis, and $\mathrm{BE}_{\mathrm{Cl}}>+5 \mathrm{mmol} / \mathrm{L}$ as hypochloremic alkalosis.

3) BE $_{\text {Lac }}=$ lactate $_{\text {normal }}$-lactate $_{\text {measured }} ;$ Lactate $_{\text {normal }}=$ $0.8 \mathrm{mmol} / \mathrm{L}$

4) $\mathrm{BE}_{\mathrm{Alb}}=(0.148 \times \mathrm{pH}-0.818) \times\left(\right.$ albumin $_{\text {normal }}$ -albumin measured $) \mathrm{BE}_{\mathrm{Alb}}>+5 \mathrm{mmol} / \mathrm{L}$ was defined as hypoalbuminemic alkalosis.

5) $\mathrm{BE}_{\mathrm{UMA}}=\mathrm{BE}-\left(\mathrm{BE}_{\mathrm{Na}}+\mathrm{BE}_{\mathrm{Cl}}+\mathrm{BE}_{\mathrm{Alb}}+\mathrm{BE}_{\mathrm{Lac}}\right) \mathrm{BE}_{\mathrm{UMA}}<-5$ $\mathrm{mmol} / \mathrm{L}$ was defined as metabolic acidosis due to unmeasured anions.

6) $\mathrm{BE}=\mathrm{BE}_{\mathrm{Na}}+\mathrm{BE}_{\mathrm{Cl}}+\mathrm{BE}_{\mathrm{Alb}}+\mathrm{BE}_{\mathrm{Lac}}+\mathrm{BE}_{\mathrm{UMA}}$

7) $\mathrm{AG}=\left[\mathrm{Na}^{+}\right]+\left[\mathrm{K}^{+}\right]-\left[\mathrm{Cl}^{-}\right]-\left[\mathrm{HCO}^{3-}\right]$

8) $\mathrm{AG}_{\text {corrected }}=\mathrm{AG}+0.25 \times(45-$ observed albumin in $\mathrm{g} / \mathrm{L})$

9) Strong ion difference-apparent (SIDa) $=\left[\mathrm{Na}^{+}\right]+\left[\mathrm{K}^{+}\right]$ $+\left[\mathrm{Ca}^{2+}\right]+\left[\mathrm{Mg}^{2+}\right]-\left[\mathrm{Cl}^{-}\right]-$lactate

10) Strong ion difference-effective (SIDe) = partial pressure of carbon dioxide $\times 2.46 \times 10^{\mathrm{pH}-8}+$ albumin $\times$ $(0.123 \times \mathrm{pH}-0.631)+2 \times$ phosphate $\times(0.309 \times \mathrm{pH}$ $-0.469)$

11) Strong ion gap (SIG) $=$ SIDa - SIDe

\section{Statistical analysis}

In the present study, continuous variables were presented as means (standard derivations) if data were normally distributed, and categorical variables were expressed by frequencies (percentages). For comparisons, the Student's $t$-test and the Mann-Whitney test was used for continuous baseline characteristics of each group for continuous variables with or without normal distribution, respectively. The $\chi^{2}$-test was performed for categorical variables. Data were compared by 
$\chi^{2}$-test for categorical variables and a one-way analysis of variance for continuous variables. Multivariate analysis was carried by Cox regression to test the association between acid-base state and ICU 30-day mortality.

The diagnostic performance was examined by area under the receiver operating characteristic curve (AUROC). The cut-off point was calculated according to the max value of Youden index, and the specificity, positive likelihood ratio, negative likelihood ratio, corresponding sensitivity, positive predictive value, and negative predictive value for relevant cut-offs were also calculated. All patients were enrolled for a comparison of diagnostic performance of the CLIF-SOFA, lactate, BE UMA, CLIF-SOFA + LAC, CLIF-SOFA + BE $E_{U M A}$ and CLIF-SOFA + LAC + BE UMA for predicting 30-day mortality rate. Statistical analyses were performed using SPSS version 22.0 software (IBM Corp., Armonk, NY, USA) and MedCalc version 12.7 (MedCalc Software, Ostend, Belgium). A two-tailed $p<0.05$ was considered to be statistically significant.

\section{Results}

\section{Baseline characteristics of CICPs with AKI}

In this study, we found that the mean age of $380 \mathrm{CICPs}$ with AKI was 57 years and $71.05 \%$ (270 of 380 ) were male. Both survivors $(n=254,66.84 \%)$ and non-survivors $(n=126$, $33.16 \%)$ had similar respective age (56.95 \pm 10.58 vs. $57.74 \pm 11.59)$ as well as sex (70.47\% vs. $72.22 \%$ males). The cause, complication and comorbidity of cirrhosis, clinical scores, as well as demographic, clinical and laboratory parameters were collected for both survivors and nonsurvivors. The patients in the non-survival group had higher morbidity rate for sepsis than those in the survival group. Other complications of individuals did not differ significantly. There is no significant difference in the demographic data and comorbidities of CICPs with AKI between the two groups.

Moreover, the etiology of AKI was determined for the survival and non-survival groups. We found that gastrointestinal bleeding predominately contributed to AKI in CICPs. Patients in the non-survival group were older, more likely to engage in alcohol abuse, and had higher mean parameters for serum lactate, bilirubin, CLIF-SOFA, MELD, SAPS II, and SOFA score than those in the survival group. The mean arterial pressure levels were lower and vasopressin use ratio was higher in the non-survivors than results in survivors.

In addition, calculations of SIDa and SIDe suggest that non-survivors had elevated SIG in comparison with survivors $(p<0.001)$. A positive value for the SIG also represented increased unmeasured anions. Furthermore, there was significant difference in the acid-base and electrolyte value for the study population between the two groups (Table 1 ).

\section{Disequilibrium of acid-base disorders in CICPs with AKI}

Net metabolic acidosis, compensated by respiratory alkalosis, was attributed to acidosis caused by unmeasured anions, hyperchloremic, lactic acidosis, and mild dilutional acidosis. In contrast, hypoalbuminemia was the only alkalinizing element that contributed to alkalosis in both groups. As illustrated in Fig. 1, non-survivors had more severe metabolic acid-base disorders than the survival group. The mean levels of $\mathrm{BE}_{\mathrm{Lac}}, \mathrm{BE}_{\mathrm{UMA}}$, and $\mathrm{BE}_{\mathrm{Na}}$ were remarkably decreased in the survival group.

\section{Acid-base state and hospital mortality in CICPs with AKI}

Mean parameters of $\mathrm{pH}_{1} \mathrm{HCO}^{3-}$, and $\mathrm{BE}$ were reduced, whereas that of AG was elevated in non-survivors because of elevated lactate and unmeasured anions. The composition frequencies of acidemia, net metabolic acidosis, lactic acidosis, acidosis based on unmeasured anions, and dilutional acidosis were significantly different between the two groups (Table 2). In a subgroup analysis, scatter plots showed observed hospital 30-day mortality rate for patients to be associated with the value of the associated acid-base marker in admission to ICU. We found a positive correlation between hospital mortality and acid-base parameters at different intervals rather than a linear trend; this suggests that fluctuation of acidotic markers may have a contributing role in hospital mortality and that maintaining these markers in the normal range could potentially reduce mortality (Fig. 2).

Moreover, hospital mortality rate was further assessed by comparing the hazard ratio in univariate and multivariate analyses. In these analyses, the presence of acidemia, acidosis owing to unmeasured anions, as well as lactic acidosis were each associated with increased ICU 30-day mortality rate with hazard ratio of 2.11 (95\% CI: $1.43-3.12), 3.38$ (95\% CI: 2.36-4.84), and 2.16 (95\% CI: $1.47-3.35)$, respectively (Table 3). After adjusting traditional confounders in model 3 , the relationship between acidosis owing to unmeasured anions with mortality rate was still significantly positive. Furthermore, the diagnostic accuracy of arterial lactate and $\mathrm{BE}_{\mathrm{UMA}}$ concentrations in predicting mortality rate is sound, with a relatively linear correlation to risk of observed mortality.

The ability to predict hospital mortality by CLIF-SOFA (with lactate: AUROC of $0.76,95 \% \mathrm{CI}: 0.71-0.81$; without lactate: AUROC of $0.74,95 \% \mathrm{CI}: 0.70-0.79$ ) showed similar strength as CLIF-SOFA + BE UMA (AUROC of $0.76,95 \%$ CI $0.71-0.80$ ). Overall, arterial lactate concentration in combination with the CLIF-SOFA and $\mathrm{BE}_{\mathrm{UMA}}$ had the strongest ability to predict 30 day mortality (AUROC of $0.79,95 \% \mathrm{CI}: 0.74-0.83$ ) (Table 4 and Fig. 3).

\section{Discussion}

Mounting evidence suggests that applying Stewart equations and the Gilfix methodology to acid-base can easily and accurately identify crucial metabolic acid-base abnormalities. $^{20}$ This method has high application in critically ill patients, but few reports on its usefulness in CICPs with AKI exist in the literature. In this study, we performed a retrospective analysis of 380 CICPs with AKI in the ICU and demonstrated that these types of patients had imbalance of metabolic acid-base.

Several significant findings emerged from our investigation. Firstly, our study showed metabolic acid-base abnormalities in non-survival and survival groups. Mean parameters of $\mathrm{pH}$, $\mathrm{HCO}^{3-}$, and $\mathrm{BE}$ were reduced, while that of $\mathrm{AG}$ was elevated in non-survivors because of increased lactate and unmeasured anions. Secondly, the SIG plays an important effect on Stewart's acid-base physiology. It is shown that an increase in SIG of non-survivors partly counteracted the decrease in partial pressure of carbon dioxide and other weak acids. Although SIG was higher in non-survivors than in survivors, it was not 
Sun D.Q. et al: Metabolic acidosis in CICPs with AKI

Table 1. Characteristics of critically ill cirrhotic patients with acute kidney injury on the first day of admission, stratified by mortality

\begin{tabular}{|c|c|c|c|}
\hline Variable & Survivors, $n=254$ & Non-survivors, $n=126$ & $p$ \\
\hline \multicolumn{4}{|l|}{ Demographic parameters } \\
\hline Age in years & $56.95 \pm 10.58$ & $57.74 \pm 11.59$ & $<0.001$ \\
\hline Sex: male, $n(\%)$ & $179(70.47 \%)$ & $91(72.22 \%)$ & 0.723 \\
\hline Height in $\mathrm{cm}$ & $172.50 \pm 8.88$ & $170.77 \pm 10.58$ & 0.199 \\
\hline Weight in $\mathrm{kg}$ & $83.67 \pm 22.08$ & $83.75 \pm 19.53$ & 0.973 \\
\hline \multicolumn{4}{|l|}{ Survival time in days } \\
\hline Death time after admission & $30.00 \pm 0.00$ & $10.39 \pm 8.12$ & $<0.001$ \\
\hline \multicolumn{4}{|l|}{ Etiology of cirrhosis, $n(\%)$} \\
\hline Alcoholic cirrhosis & $104(40.94 \%)$ & $72(57.14 \%)$ & 0.030 \\
\hline Non-alcoholic cirrhosis & $138(54.33 \%)$ & $50(39.68 \%)$ & 0.005 \\
\hline Biliary cirrhosis & $8(3.14 \%)$ & $3(2.38 \%)$ & 0.674 \\
\hline Viral cirrhosis & $4(1.57 \%)$ & $1(0.79 \%)$ & 0.529 \\
\hline \multicolumn{4}{|l|}{ Etiology of AKI, $n(\%)$} \\
\hline Sepsis & $37(14.57 \%)$ & $50(39.68 \%)$ & $<0.001$ \\
\hline Heart failure & $12(4.72 \%)$ & $6(4.76 \%)$ & 0.987 \\
\hline Gastrointestinal bleeding & $88(34.65 \%)$ & $48(38.10 \%)$ & 0.509 \\
\hline Respiratory failure & $10(3.93 \%)$ & $5(3.97 \%)$ & 0.988 \\
\hline Hepatology renal syndrome & $76(29.92 \%)$ & $45(35.71 \%)$ & 0.224 \\
\hline Obstructive kidney disease & $2(0.79 \%)$ & $1(0.79 \%)$ & 0.995 \\
\hline \multicolumn{4}{|l|}{ Complication } \\
\hline Sepsis & $37(14.57 \%)$ & $50(39.68 \%)$ & $<0.001$ \\
\hline Gastrointestinal bleeding & $88(34.65 \%)$ & $48(38.10 \%)$ & 0.509 \\
\hline Hepatic coma & $22(8.67 \%)$ & $6(4.76 \%)$ & 0.710 \\
\hline Spontaneous peritonitis & $1(0.39 \%)$ & $2(1.59 \%)$ & 0.216 \\
\hline Respiratory failure & $10(3.93 \%)$ & $5(3.97 \%)$ & 0.988 \\
\hline \multicolumn{4}{|l|}{ Comorbidity } \\
\hline Cardiac arrhythmias & $36(14.17 \%)$ & $21(16.67 \%)$ & 0.522 \\
\hline Chronic pulmonary disease & $32(12.60 \%)$ & $22(17.46 \%)$ & 0.201 \\
\hline Lymphoma & $1(0.39 \%)$ & $1(0.79 \%)$ & 0.612 \\
\hline Solid tumor & $55(21.65 \%)$ & $21(16.67 \%)$ & 0.253 \\
\hline Deficiency anemias & $35(13.78 \%)$ & $16(12.70 \%)$ & 0.771 \\
\hline Hypertension & $76(29.92 \%)$ & $28(22.22 \%)$ & 0.113 \\
\hline Diabetes Mellitus & $68(26.77 \%)$ & $25(19.84 \%)$ & 0.139 \\
\hline \multicolumn{4}{|l|}{ Ethnicity, $n(\%)$} \\
\hline White & $192(75.59 \%)$ & $81(64.29 \%)$ & \\
\hline African black & $17(6.69 \%)$ & $12(9.52 \%)$ & 0.070 \\
\hline Other & $45(17.72 \%)$ & $33(26.19 \%)$ & \\
\hline \multicolumn{4}{|l|}{ Clinical parameters } \\
\hline Heart rate, n. & $91.88 \pm 18.93$ & $94.25 \pm 19.55$ & 0.257 \\
\hline Respiratory rate & $41.57 \pm 33.83$ & $38.14 \pm 32.06$ & 0.346 \\
\hline Temperature in ${ }^{\circ} \mathrm{C}$ & $36.75 \pm 0.82$ & $36.36 \pm 1.20$ & \\
\hline $\mathrm{SBP}$ in $\mathrm{mmHg}$ & $123.99 \pm 24.30$ & $112.49 \pm 19.27$ & 0.001 \\
\hline $\mathrm{DBP}$ in $\mathrm{mmHg}$ & $65.45 \pm 16.47$ & $56.95 \pm 14.90$ & $<0.001$ \\
\hline MAP in $\mathrm{mmHg}$ & $84.96 \pm 17.22$ & $75.47 \pm 14.13$ & $<0.001$ \\
\hline
\end{tabular}


Table 1. (continued)

\begin{tabular}{|c|c|c|c|}
\hline Variable & Survivors, $n=254$ & Non-survivors, $n=126$ & $p$ \\
\hline Vasopressin used, $n(\%)$ & $96(37.80 \%)$ & $84(66.67 \%)$ & $<0.001$ \\
\hline \multicolumn{4}{|l|}{ Laboratory parameters } \\
\hline Glucose in mg/dL & $141.28 \pm 76.54$ & $123.60 \pm 62.12$ & 0.025 \\
\hline White blood cell as $10^{9} / \mathrm{L}$ & $10.58 \pm 6.23$ & $12.28 \pm 7.65$ & 0.021 \\
\hline Platelet as $10^{9} / \mathrm{L}$ & $159.56 \pm 108.66$ & $119.43 \pm 72.71$ & $<0.001$ \\
\hline INR & $1.65 \pm 0.57$ & $2.45 \pm 1.69$ & $<0.001$ \\
\hline Bilirubin in $\mathrm{mg} / \mathrm{dL}$ & $3.46 \pm 5.32$ & $8.09 \pm 10.03$ & $<0.001$ \\
\hline Urine output in $\mathrm{mL}$ & $1560.17 \pm 2188.48$ & $1332.92 \pm 1868.41$ & 0.319 \\
\hline $\mathrm{pH}$ & $7.39 \pm 0.08$ & $7.35 \pm 0.11$ & $<0.001$ \\
\hline $\mathrm{PaCO}_{2}$ in $\mathrm{mmHg}$ & $38.11 \pm 9.09$ & $35.95 \pm 8.86$ & 0.029 \\
\hline $\mathrm{HCO}^{3-}$ in $\mathrm{mmol} / \mathrm{L}$ & $22.53 \pm 4.96$ & $19.54 \pm 5.67$ & $<0.001$ \\
\hline $\mathrm{BE}$ in $\mathrm{mmol} / \mathrm{L}$ & $-1.20 \pm 4.62$ & $-4.70 \pm 6.25$ & $<0.001$ \\
\hline $\mathrm{Na}^{+}$in $\mathrm{mmol} / \mathrm{L}$ & $138.49 \pm 4.94$ & $135.54 \pm 6.98$ & $<0.001$ \\
\hline $\mathrm{Cl}^{-}$in $\mathrm{mmol} / \mathrm{L}$ & $106.16 \pm 6.08$ & $102.60 \pm 8.23$ & $<0.001$ \\
\hline $\mathrm{K}^{+}$in $\mathrm{mmol} / \mathrm{L}$ & $4.11 \pm 0.73$ & $4.52 \pm 0.87$ & $<0.001$ \\
\hline $\mathrm{Ca}^{2+}$ in $\mathrm{mmol} / \mathrm{L}$ & $1.11 \pm 0.13$ & $1.04 \pm 0.14$ & $<0.001$ \\
\hline $\mathrm{Mg}^{2+}$ in $\mathrm{mmol} / \mathrm{L}$ & $0.78 \pm 0.20$ & $0.85 \pm 0.19$ & 0.001 \\
\hline $\mathrm{Pi}$ in $\mathrm{mmol} / \mathrm{L}$ & $1.13 \pm 0.48$ & $1.62 \pm 0.73$ & $<0.001$ \\
\hline Alb in $\mathrm{g} / \mathrm{L}$ & $29.58 \pm 6.44$ & $25.71 \pm 6.01$ & $<0.001$ \\
\hline Lactate, $\mathrm{mmol} / \mathrm{L}$ & $2.80 \pm 2.26$ & $4.77 \pm 3.81$ & $<0.001$ \\
\hline Creatinine in $\mathrm{mg} / \mathrm{dL}$ & $2.31 \pm 1.78$ & $2.12 \pm 1.77$ & 0.343 \\
\hline eGFR in $\mathrm{mL} / \mathrm{min} / 1.73 \mathrm{~m}^{2}$ & $48.40 \pm 33.04$ & $50.49 \pm 31.72$ & 0.556 \\
\hline BUN in $\mathrm{mmol} / \mathrm{L}$ & $26.52 \pm 21.44$ & $42.62 \pm 29.69$ & $<0.001$ \\
\hline SBE in $\mathrm{mmol} / \mathrm{L}$ & $-2.44 \pm 5.54$ & $-6.11 \pm 6.93$ & $<0.001$ \\
\hline AG in $\mathrm{mmol} / \mathrm{L}$ & $13.92 \pm 4.76$ & $17.92 \pm 7.13$ & $<0.001$ \\
\hline AGcorr in $\mathrm{mmol} / \mathrm{L}$ & $19.17 \pm 5.49$ & $23.45 \pm 7.48$ & $<0.001$ \\
\hline SIDa in $\mathrm{mEq} / \mathrm{L}$ & $35.47 \pm 4.92$ & $34.40 \pm 5.23$ & 0.053 \\
\hline SIDe in $\mathrm{mEq} / \mathrm{L}$ & $31.69 \pm 6.41$ & $29.06 \pm 6.10$ & $<0.001$ \\
\hline SIG in $\mathrm{mEq} / \mathrm{L}$ & $3.78 \pm 5.47$ & $5.28 \pm 4.77$ & 0.011 \\
\hline \multicolumn{4}{|l|}{ Clinical scores } \\
\hline CLIF-SOFA & $8.80 \pm 3.21$ & $12.01 \pm 3.57$ & $<0.001$ \\
\hline MELD & $14.93 \pm 8.86$ & $25.26 \pm 12.38$ & $<0.001$ \\
\hline SAPSII & $44.50 \pm 13.84$ & $53.10 \pm 14.53$ & $<0.001$ \\
\hline SOFA & $7.59 \pm 3.09$ & $10.35 \pm 3.47$ & $<0.001$ \\
\hline
\end{tabular}

Abbreviations: CLIF-SOFA, chronic liver failure-sequential organ failure assessment score; DBP, diastolic blood pressure; INR, international normalized ratio; MELD, model for end-stage liver disease; SBP, systolic blood pressure; MAP, mean arterial pressure; SAPSII, simplified acute physiology score; $B$ UN, blood urea nitrogen; PaO ${ }_{2}$, partial pressure of oxygen; $\mathrm{PaCO}_{2}$, partial pressure of carbon dioxide; $\mathrm{FIO}_{2}$, fraction of inspiration $\mathrm{O}_{2} ; \mathrm{BE}$, base excess; $\mathrm{SBE}$, standard base excess; $\mathrm{Na}^{+}$, sodium; $\mathrm{Cl}^{-}$, chloride; $\mathrm{Alb}$, albumin; $\mathrm{Ca}^{2+}$, ionized calcium; $\mathrm{Pi}$, inorganic phosphate; $\mathrm{Mg}^{2+}$, magnesium; AG, anion gap; SID, strong ion difference; SIDa, the apparent SID; SIDe, the effective SID; UMA, unmeasured anions; AGcorr, anion gap corrected for albumin; eGFR, evaluated glomerular filter rate; AKI, acute kidney injury.

a pivotal predictor of outcome in our study. Thirdly, the development of acidemia, mainly attributed to increased unmeasured anions and lactic acidosis, had a positive relationship, independently, with increased ICU 30-day mortality.

Our finding confirmed that CICPs with AKI is a state of metabolic acidosis. We found decreases in $\mathrm{pH} \mathrm{HCO}^{3-}, \mathrm{BE}$, $\mathrm{BE}_{\mathrm{UMA}}$, and chloride levels, as well as increases in lactate and SIG in the non-survival group. In addition, the components determining $B E$ and the effect of changes in albumin, sodium, lactate and chloride levels were analyzed and quantified. We demonstrated that these parameters were positively correlated with hospital mortality and that the frequencies of net metabolic acidosis, acidosis owing to unmeasured anions, and lactic acidosis were higher in nonsurvivors. Thus, understanding lactic acidosis and components of unmeasured anions is crucial in these patients.

In the normal physiologic state, a total amount of $1500 \mathrm{mmol}$ of lactate is produced in the human body daily 
A

\section{non-Survival}

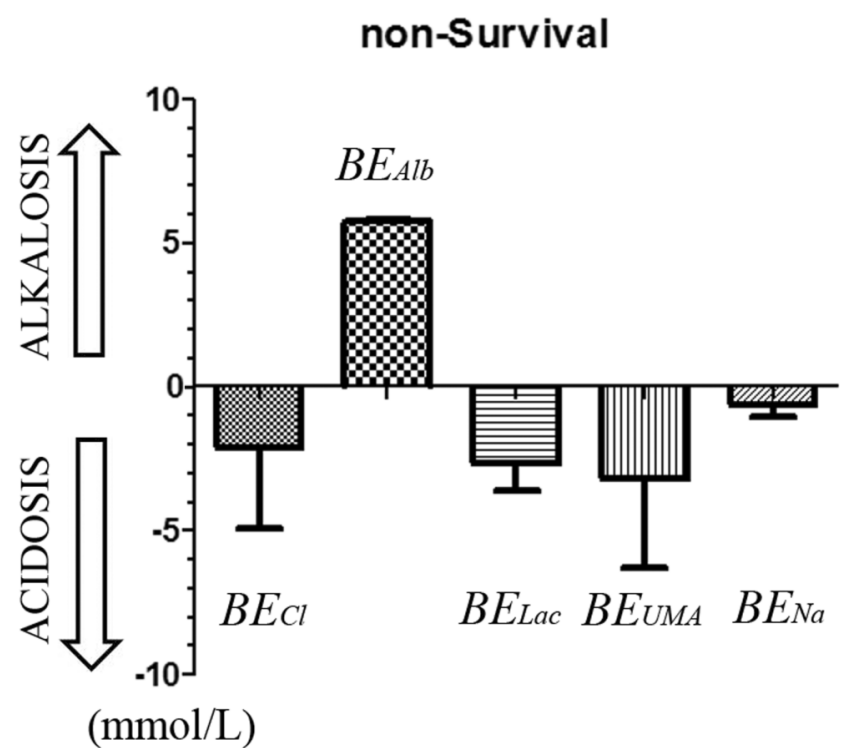

$\mathrm{B}$

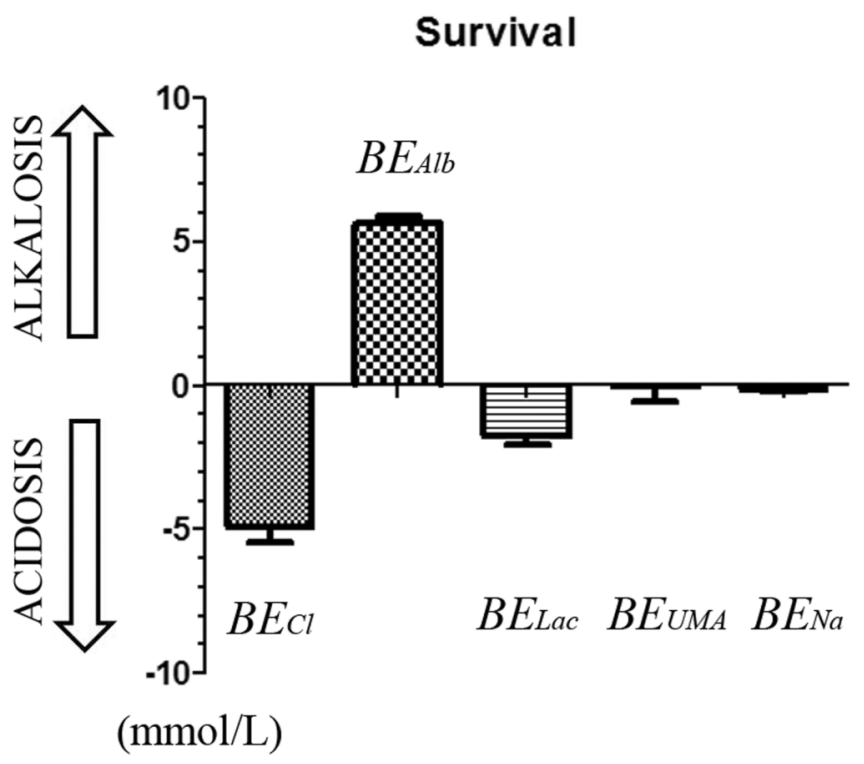

Fig. 1. Disequilibrium of metabolic acid-base disorders in CICPs with AKI between non-survivors and survivors. Acidosis owing to unmeasured anions and lactate, hyperchloremic acidosis and dilutional acidosis outweigh hypoalbuminemic alkalosis, resulting in net metabolic acidosis. Metabolic acid-base analysis was performed applying Gilfix methodology, based on the concept that net base excess $(B E)$ is determined by effect of free water excess ( $\left.B E_{N a}\right)$, changes in concentrations of chloride $\left(B E_{C I}\right)$, albumin $\left(\mathrm{BE}_{\mathrm{Alb}}\right)$, lactate $\left(\mathrm{BE}_{\mathrm{Lac}}\right)$ and the accumulation of unmeasured anions $\left(\mathrm{BE}_{\mathrm{UMA}}\right): \mathrm{BE}=\mathrm{BE}_{\mathrm{Na}}+\mathrm{BE}_{\mathrm{Cl}}+\mathrm{BE}_{\mathrm{Alb}}+\mathrm{BE}_{\mathrm{Lac}}+\mathrm{BE} \mathrm{E}_{\mathrm{UMA}}$.

from the reduction of pyruvate by enzyme lactate dehydrogenase, with lactate levels maintained at $<2 \mathrm{mmol} / \mathrm{L}^{21}$ However, in pathological conditions exposed to tissue hypoxia and anaerobic state, pyruvate is promptly accumulated and its metabolism is almost entirely shifted to lactate production. ${ }^{22-24}$ In physiological conditions, the generation and consumption of lactate are strictly balanced. The liver and kidney are well known for lactate dehydrogenase dysfunction in the setting of CICPs with AKI. 22,25 Therefore, hyperlactatemia is common in CICPs with AKI and elevated serum lactate can gradually increase hospital mortality. The elevation of lactate can result from both increased lactate production and decreased hepatic lactate elimination. Moreover, patients who suffer from sepsis might also partly interpret the production of lactate. In our previous study, we revealed that initial lactate concentration strongly and independently predicted short- and long-term hospital outcome in CICPs with AKI. ${ }^{16}$

In our evaluation of components contributing to $B E$, we discovered that CICPs with AKI had significant hypoalbuminemic alkalosis in combination with acidosis owing to unmeasured anions, even after adjusting for confounders. In the non-survival group, acidosis secondary to unmeasured anions was found to be significant, and hospital mortality was notably higher as $\mathrm{BE}_{\mathrm{UMA}}$ value became lower than $-4.14 \mathrm{mmol} / \mathrm{L}$. Some unmeasured anions might be the result of retained organic anions, attributed to AKI, during BE UmA evaluation. ${ }^{26}$ Furthermore, among the examined acid-base parameters, $\mathrm{BE}_{\mathrm{UMA}}$ had the best discrimination and did not differ significantly with CLIF-SOFA. Thus, BE UMA in combination with lactate levels and CLIF-SOFA score have markedly reinforced our ability to predict mortality in CICPS

Table 2. Frequencies of acid-base disorders with critically ill cirrhosis with AKI, stratified by mortality

\begin{tabular}{llll}
\hline & Survivors, $n=254$ & Non-survivors, $n=126$ & $p$ \\
\hline Acidemia & $70(27.5 \%)$ & $59(46.82 \%)$ & $<0.001$ \\
Alkalemia & $58(22.8 \%)$ & $23(18.3 \%)$ & 0.674 \\
Net metabolic acidosis & $46(18.11 \%)$ & $52(41.27 \%)$ & $<0.001$ \\
Dilutional acidosis & $3(1.18 \%)$ & $5(3.97 \%)$ & 0.075 \\
Net metabolic alkalosis & $17(6.69 \%)$ & $7(5.56 \%)$ & 0.733 \\
Hyperchloremic acidosis & $115(45.28 \%)$ & $37(29.37 \%)$ & 0.254 \\
Hypochloremic alkalosis & $30(11.81 \%)$ & $42(33.33 \%)$ & $<0.001$ \\
Acidosis owing to unmeasured anions & $64(25.20 \%)$ & $77(61.11 \%)$ & $<0.001$ \\
Hypoalbuminemic alkalosis & $114(44.88 \%)$ & $77(61.11 \%)$ & 0.003 \\
Lactic acidosis & $124(48.82 \%)$ & $88(69.84 \%)$ & $<0.001$ \\
\hline
\end{tabular}


A

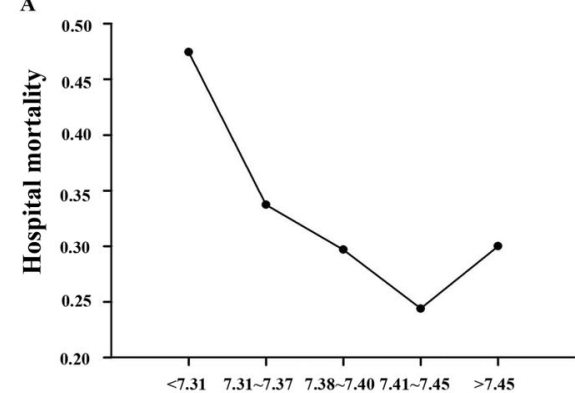

C

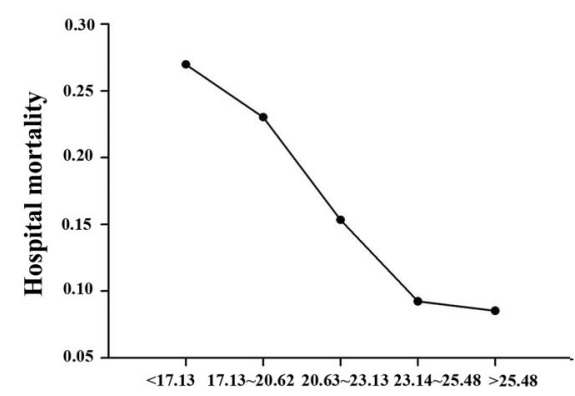

E

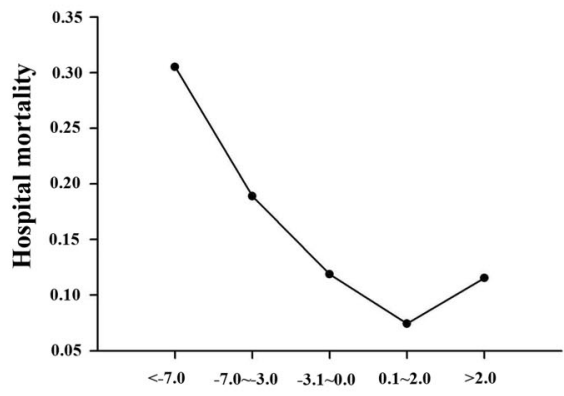

BE groups (mmol/L)

G

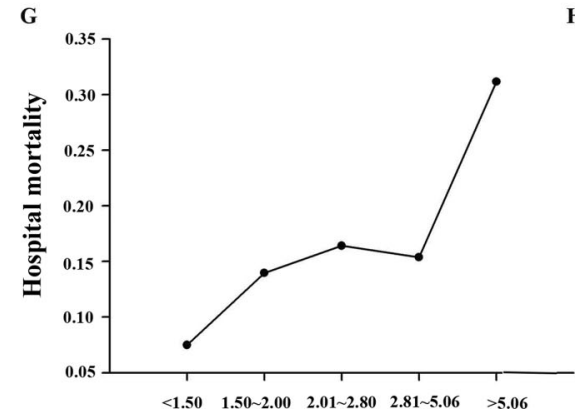

Lactate groups $(\mathrm{mmol} / \mathrm{L})$
B

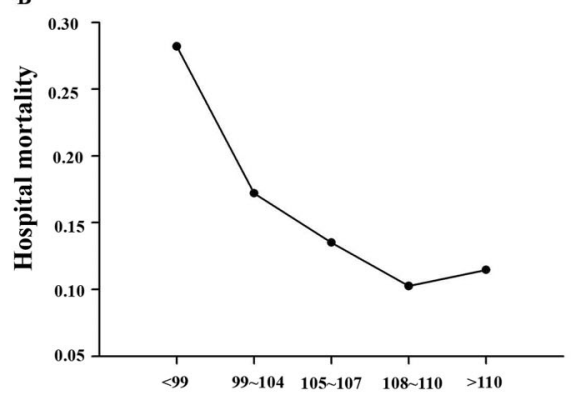

Chloride groups (mmol/L)

D

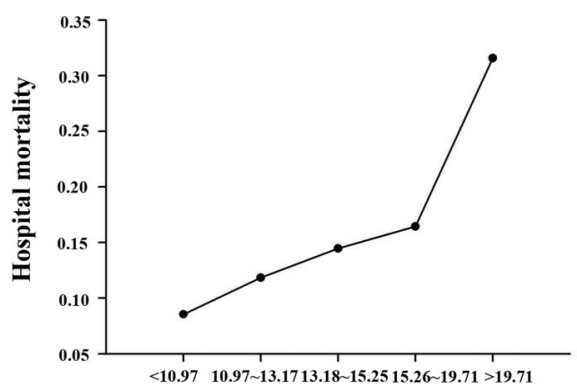

F

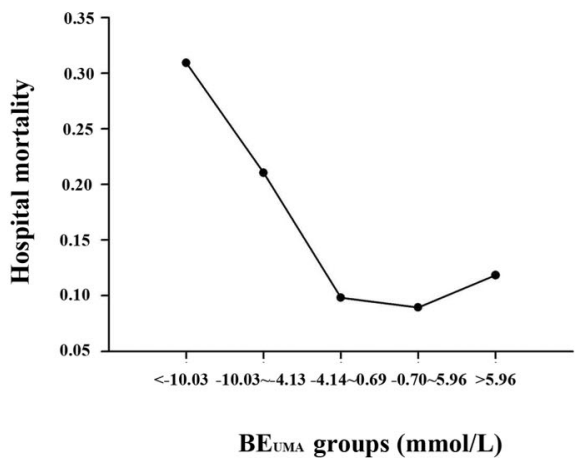

H

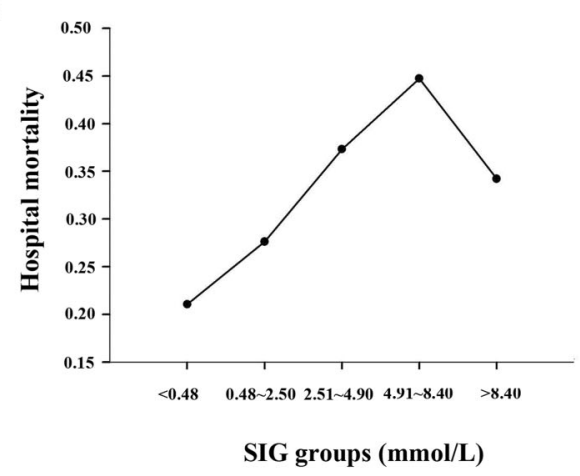

Fig. 2. The 30-day hospital mortality of the associated acid-base marker in different intervals. 
Sun D.Q. et al: Metabolic acidosis in CICPs with AKI

Table 3. Association of acid-base state with ICU 30-day mortality in critically ill cirrhotic patients with AKI

\begin{tabular}{|c|c|c|c|c|c|c|}
\hline & Model 1 & $p$ & Model 2 & $p$ & Model 3 & $p$ \\
\hline Acidemia & $\begin{array}{l}2.11 \\
(1.43-3.12)\end{array}$ & $<0.001$ & $\begin{array}{l}1.67 \\
(0.99-2.78)\end{array}$ & 0.051 & $\begin{array}{l}0.98 \\
(0.50-1.91)\end{array}$ & 0.948 \\
\hline Alkalemia & $\begin{array}{l}1.11 \\
(0.67-1.84)\end{array}$ & 0.684 & $\begin{array}{l}0.73 \\
(0.34-1.57)\end{array}$ & 0.422 & $\begin{array}{l}1.64 \\
(0.47-5.55)\end{array}$ & 0.424 \\
\hline Net metabolic acidosis & $\begin{array}{l}2.65 \\
(1.84-3.81)\end{array}$ & $<0.001$ & $\begin{array}{l}2.10 \\
(1.26-3.49)\end{array}$ & 0.004 & $\begin{array}{l}0.91 \\
(0.48-1.75)\end{array}$ & 0.914 \\
\hline Dilutional acidosis & $\begin{array}{l}2.18 \\
(0.89-5.34)\end{array}$ & 0.088 & $\begin{array}{l}1.20 \\
(0.27-5.27)\end{array}$ & 0.811 & $\begin{array}{l}1.38 \\
(0.25-7.52)\end{array}$ & 0.711 \\
\hline Hyperchloremic acidosis & $\begin{array}{l}0.78 \\
(0.51-1.20)\end{array}$ & 0.263 & $\begin{array}{l}0.66 \\
(0.37-1.17)\end{array}$ & 0.154 & $\begin{array}{l}0.68 \\
(0.33-1.40)\end{array}$ & 0.680 \\
\hline Hypochloremic alkalosis & $\begin{array}{l}2.45 \\
(1.61-3.71)\end{array}$ & $<0.001$ & $\begin{array}{l}1.57 \\
(0.86-2.87)\end{array}$ & 0.141 & $\begin{array}{l}1.19 \\
(0.53-2.68)\end{array}$ & 0.670 \\
\hline $\begin{array}{l}\text { Acidosis owing to } \\
\text { unmeasured anions }\end{array}$ & $\begin{array}{l}3.38 \\
(2.36-4.84)\end{array}$ & $<0.001$ & $\begin{array}{l}3.20 \\
(1.96-5.24)\end{array}$ & $<0.001$ & $\begin{array}{l}2.29 \\
(1.22-4.30)\end{array}$ & 0.010 \\
\hline Hypoalbuminemic alkalosis & $\begin{array}{l}1.75 \\
(1.22-2.50)\end{array}$ & 0.002 & $\begin{array}{l}1.81 \\
(1.11-2.94)\end{array}$ & 0.017 & $\begin{array}{l}0.80 \\
(0.35-1.83)\end{array}$ & 0.598 \\
\hline Lactic acidosis & $\begin{array}{l}2.16 \\
(1.47-3.15)\end{array}$ & $<0.001$ & $\begin{array}{l}1.58 \\
(0.97-2.56)\end{array}$ & 0.065 & $\begin{array}{l}0.85 \\
(0.37-1.93)\end{array}$ & 0.691 \\
\hline
\end{tabular}

Model 1 is univariate analysis. Model 2 includes Model 1 plus age, sex, height, weight and complication (hypertension, diabetes mellitus, cardiac arrhythmias, chronic pulmonary disease, lymphoma, solid tumor, and iron deficiency anemias). Model 3 includes Model 2 plus comorbidities (sepsis, gastrointestinal bleeding, respiratory failure, hepatic coma, and spontaneous peritonitis), cause of liver cirrhosis (alcoholic cirrhosis, non-alcoholic cirrhosis, biliary cirrhosis, and viral cirrhosis), laboratory parameters (eGFR, white blood cell, platelet, albumin, lactate, and hematocrit), and chronic liver failure-sequential organ failure assessment score.

with AKI. As a secondary outcome, we found that decreased serum albumin was associated with abnormal liver function and expenditure, which might possibly indicate a need for nutrition assessment. All together, these observations emphasize that imbalance of the acid-base state reflects hospital mortality of CICPs with AKI.

A few potential limitations exist in our study. Firstly, we recognize that the results from a single center may not fully reflect all the subjects' conditions. Secondly, sequential measurement of acid-base disorders may provide a better insight into the mechanisms of metabolic acidosis. Thirdly, specific treatments of acid-base disorders benefiting CICPs with AKI are yet to be defined.

In conclusion, this study confirmed that CICPs with AKI exhibit a complex metabolic acidosis during ICU admission. There was highly significant difference between the survivors and the non-survivors for lactate and $\mathrm{BE}_{\mathrm{UMA}}$ of acid-base state in the CICPs with AKI, which can be used to determine mortality outcome. This physiochemical methodology to assess acid-base disorders showed great value with important prognostic implication, thus highlighting the need to control metabolic acidosis.

Table 4. Performance of different prognostic models in predicting 30-day mortality using the optimal cut-off point

\begin{tabular}{|c|c|c|c|c|c|c|c|c|c|c|}
\hline $\begin{array}{l}\text { Prognostic } \\
\text { model }\end{array}$ & AUROC & $95 \% \mathrm{CI}$ & $\begin{array}{l}p \text { (vs. } \\
\text { CLIF- } \\
\text { SOFA) }\end{array}$ & Cut-off & $\begin{array}{l}\text { Sensitivity, } \\
\%\end{array}$ & $\begin{array}{l}\text { Specificity, } \\
\%\end{array}$ & PLR & NLR & PPV & NPV \\
\hline CLIF-SOFA & 0.74 & $0.70-0.79$ & & 12.00 & 49.21 & 87.01 & 3.79 & 0.58 & 65.30 & 77.50 \\
\hline LAC & 0.68 & $0.63-0.73$ & 0.008 & 2.50 & 62.61 & 65.37 & 1.81 & 0.57 & 47.40 & 77.80 \\
\hline $\mathrm{BE}_{\mathrm{UMA}}$ & 0.69 & $0.64-0.74$ & 0.171 & -4.63 & 62.40 & 74.41 & 2.44 & 0.51 & 54.50 & 80.10 \\
\hline $\begin{array}{l}\text { CLIF-SOFA + } \\
\text { LAC }\end{array}$ & 0.76 & $0.71-0.81$ & 0.049 & 3.79 & 56.80 & 83.46 & 3.44 & 0.52 & 62.80 & 79.70 \\
\hline $\begin{array}{l}\text { CLIF-SOFA + } \\
\text { BE UMA }^{\text {UnA }}\end{array}$ & 0.76 & $0.71-0.80$ & 0.731 & 0.78 & 68.80 & 77.95 & 3.12 & 0.40 & 60.60 & 83.50 \\
\hline $\begin{array}{l}\text { CLIF-SOFA + } \\
\text { LAC + BE UMA }\end{array}$ & 0.79 & $0.74-0.83$ & $<0.001$ & 2.79 & 56.00 & 87.80 & 4.59 & 0.50 & 69.30 & 80.20 \\
\hline
\end{tabular}

Abbreviations: CLIF-SOFA, chronic liver failure-sequential organ failure assessment score; LAC, lactate; NLR, negative likelihood ratio; NPV, negative predictive value; PLR, positive likelihood ratio; PPV, positive predictive value. 


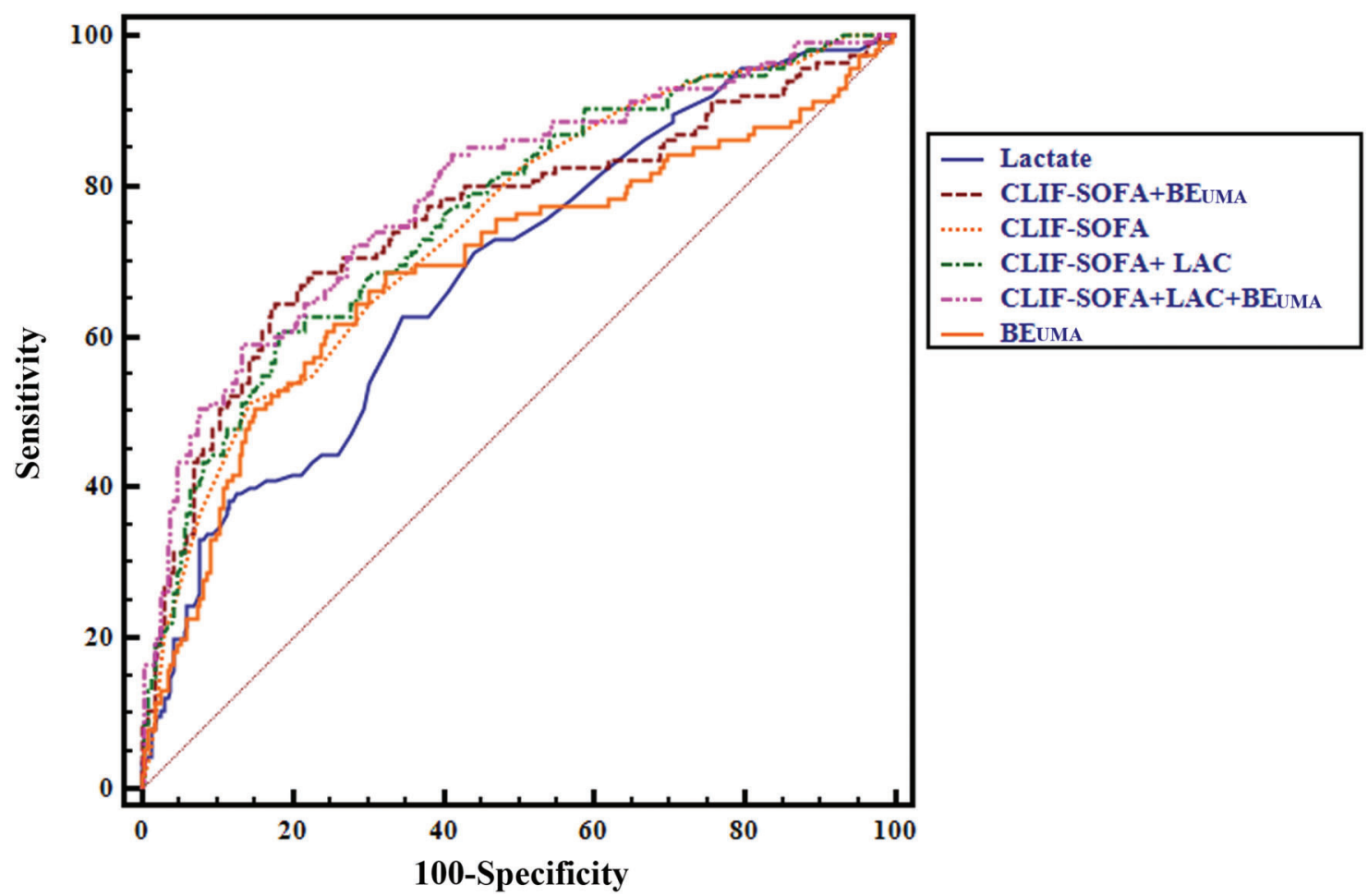

Fig. 3. Area under the receiver operating characteristic curve analysis of different models in predicting 30-day mortality. Chronic liver failure-sequential organ failure assessment (CLIF-SOFA) showed improvement in discriminative ability by combining lactate and BEuMA, as compared with CLIF-SOFA alone.

\section{Acknowledgment}

This work was supported by grants from the General Program of Science and Technology Development Foundation of Nanjing Medical University (2017NJMU168) and the Zhejiang Engineering Research Center of Intelligent Medicine (2016E10011), The First Affiliated Hospital of Wenzhou Medical University.

\section{Conflict of interest}

The authors have no conflict of interests related to this publication.

\section{Author contributions}

Designed the study, interpreted the data, and wrote the manuscript (DQS, LZ, CFZ), performed the statistical analyses and collected the data (WYL), revised the manuscript (KIZ), designed the study, allocated the funding, reviewed the results, and finalized the manuscript (WJY, XMC), reviewed the results and finalized the manuscript (MHZ). All authors read and approved the final version of the paper.

\section{References}

[1] Chawla LS, Bellomo R, Bihorac A, Goldstein SL, Siew ED, Bagshaw SM, et al. Acute kidney disease and renal recovery: consensus report of the Acute Disease Quality Initiative (ADQI) 16 Workgroup. Nat Rev Nephrol 2017;13: 241-257. doi: 10.1038/nrneph.2017.2

[2] Ferrarese A, Feltracco P, Barbieri S, Cillo U, Burra P, Senzolo M. Outcome of critically ill cirrhotic patients admitted to the ICU: The role of ACLF. J Hepatol 2019;70:801-803. doi: 10.1016/j.jhep.2018.09.015.
[3] Nadim MK, Durand F, Kellum JA, Levitsky J, O'Leary JG, Karvellas C], et al. Management of the critically ill patient with cirrhosis: A multidisciplinary perspective. J Hepatol 2016;64:717-735. doi: 10.1016/j.jhep.2015.10.019.

[4] Drolz A, Horvatits T, Roedl K, Rutter K, Brunner R, Zauner C, et al. Acid-base status and its clinical implications in critically ill patients with cirrhosis, acuteon-chronic liver failure and without liver disease. Ann Intensive Care 2018; 8: 48. doi: 10.1186/s13613-018-0391-9.

[5] Scheiner B, Lindner G, Reiberger T, Schneeweiss B, Trauner M, Zauner C, et al. Acid-base disorders in liver disease. J Hepatol 2017;67:1062-1073. doi: $10.1016 / j$.jhep.2017.06.023.

[6] Mallat J, Michel D, Salaun P, Thevenin D, Tronchon L. Defining metabolic acidosis in patients with septic shock using Stewart approach. Am J Emerg Med 2012;30:391-398. doi: 10.1016/j.ajem.2010.11.039.

[7] Morgan TJ. Partitioning standard base excess: a new approach. J Clin Monit Comput 2011;25:349-352. doi: 10.1007/s10877-011-9324-y.

[8] Figge J, Rossing TH, Fencl V. The role of serum proteins in acid-base equilibria. J Lab Clin Med 1991;117:453-467.

[9] Stewart PA. Modern quantitative acid-base chemistry. Can J Physiol Pharmacol 1983;61:1444-1461.

[10] Gilfix BM, Bique M, Magder S. A physical chemical approach to the analysis of acid-base balance in the clinical setting. J Crit Care 1993;8:187-197. doi: 10.1016/0883-9441(93)90001-2.

[11] Lim HS, Howell N. Cardiogenic shock due to end-stage heart failure and acute myocardial infarction: Characteristics and outcome of temporary mechanical circulatory support. Shock 2018;50:167-172. doi: 10 . 1097/SHK.0000000000001052.

[12] Ortner CM, Combrinck B, Allie S, Story D, Landau R, Cain K, et al. Strong ion and weak acid analysis in severe preeclampsia: potential clinical significance. $\mathrm{Br}$ J Anaesth 2015;115:275-284. doi: 10.1093/bja/aev221.

[13] Ho KM, Lan NS, Williams TA, Harahsheh Y, Chapman AR, Dobb G], et al. A comparison of prognostic significance of strong ion gap (SIG) with other acid-base markers in the critically ill: a cohort study. J Intensive Care 2016;4:43. doi: 10.1186/s40560-016-0166-z.

[14] Funk GC, Doberer D, Kneidinger N, Lindner G, Holzinger U, Schneeweiss B. Acid-base disturbances in critically ill patients with cirrhosis. Liver Int 2007; 27:901-909. doi: 10.1111/j.1478-3231.2007.01510.x.

[15] Sun DQ, Zheng CF, Liu WY, Van Poucke S, Mao Z, Shi KQ, et al. AKI-CLIFSOFA: a novel prognostic score for critically ill cirrhotic patients with acute kidney injury. Aging (Albany NY) 2017;9:286-296. doi: 10.18632/aging. 101161. 
[16] Sun DQ, Zheng CF, Lu FB, Van Poucke S, Chen XM, Chen YP, et al. Serum lactate level accurately predicts mortality in critically ill patients with cirrhosis with acute kidney injury. Eur J Gastroenterol Hepatol 2018;30:13611367. doi: 10.1097/MEG.0000000000001189.

[17] Lameire N, Kellum JA. Contrast-induced acute kidney injury and renal support for acute kidney injury: a KDIGO summary (Part 2). Crit Care 2013;17:205. doi: 10.1186/cc11455.

[18] Rosi S, Piano S, Frigo AC, Morando F, Fasolato S, Cavallin M, et al. New ICA criteria for the diagnosis of acute kidney injury in cirrhotic patients: can we use an imputed value of serum creatinine? Liver Int 2015;35:2108-2114. doi: 10.1111 /liv. 12852 .

[19] Siggaard-Andersen O, Wimberley PD, Fogh-Andersen N, Gøthgen IH. Measured and derived quantities with modern $\mathrm{pH}$ and blood gas equipment: $\mathrm{Cal}$ culation algorithms with 54 equations. Scandinavian Journal of Clinical and Laboratory Investigation 1988;48:7-15, doi: 10.1080/00365518809168181.

[20] Antonogiannaki EM, Mitrouska I, Amargianitakis V, Georgopoulos D. Evaluation of acid-base status in patients admitted to ED-physicochemical vs traditional approaches. Am J Emerg Med 2015;33:378-382. doi: 10.1016/j. ajem.2014.12.010.
[21] Philp A, Macdonald AL, Watt PW. Lactate-a signal coordinating cell and systemic function. J Exp Biol 2005;208:4561-4575. doi: 10.1242/jeb.01961.

[22] Levy B, Gibot S, Franck P, Cravoisy A, Bollaert PE. Relation between muscle $\mathrm{Na}+\mathrm{K}+$ ATPase activity and raised lactate concentrations in septic shock: a prospective study. Lancet 2005;365:871-875. doi: 10.1016/S0140-6736 (05) $71045-X$.

[23] Aramburo A, Todd J, George EC, Kiguli S, Olupot-Olupot P, Opoka RO, et al. Lactate clearance as a prognostic marker of mortality in severely ill febrile children in East Africa. BMC Med 2018;16:37. doi: 10.1186/s12916-018-1014-x.

[24] Hernandez G, Bellomo R, Bakker J. The ten pitfalls of lactate clearance in sepsis. Intensive Care Med 2019;45:82-85. doi: 10.1007/s00134-018-5213-x.

[25] Levy B, Sadoune LO, Gelot AM, Bollaert PE, Nabet P, Larcan A. Evolution of lactate/pyruvate and arterial ketone body ratios in the early course of catecholamine-treated septic shock. Crit Care Med 2000;28:114-119. doi: 10. 1097/00003246-200001000-00019.

[26] Rocktaeschel J, Morimatsu H, Uchino S, Goldsmith D, Poustie S, Story D, et al. Acid-base status of critically ill patients with acute renal failure: analysis based on Stewart-Figge methodology. Crit Care 2003;7:R60. doi: 10. $1186 / \mathrm{cc} 2333$ 